\title{
Open-ended Problems in Dynamics - Rendering Solution Manuals Ineffective
}

\section{Dr. Bidhan C. Roy, University of Wisconsin, Platteville}

Bidhan Roy (Ph.D. 2003, UIUC) is an Associate Professor with the Department of Mechanical Engineering, University of Wisconsin, Platteville. His research interests are primarily in mechanics with a focus on biological systems, applied mathematics, and numerical methods. 


\section{Open-Ended Problems in Dynamics - Rendering Solution Manuals Ineffective}

At the University of Wisconsin -Platteville, a course in Engineering Mechanics -Dynamics is a pre-requisite for future courses in Dynamical Systems, Fluid Dynamics, and Mechanisms and Machines. Therefore, it is imperative for students to develop their conceptual understandings of the course contents. This can aid in their critical thinking abilities. Problem solving is a very important step in this direction and homework problems play a vital role in this regard. However, online solution manuals readily available to students provides a convenient step to complete homework assignments. Several students merely replicate the steps in problem solving from a solution manual without any understanding of the process. This hampers their learning of the topic at hand and has a negative impact on their grades. Taking a cue from studies in educational psychology (and as also reported in the 2012 NAS report "Discipline-Based Educational Research: Understanding and Improving Learning in Undergraduate Science and Engineering"), changing problem features and making them more open-ended engages students to think critically and improves their learning. Problem features that can be changed may include the format of the problem statement, familiarity with problem context, and whether the values are numeric or symbolic. Changing problem features and making them more open-ended minimizes the use of solution manual. Such an exercise is currently in progress. Assessment of the progress made has been confined to data based on student performance (scores) in their homework, quiz, and exams. In addition, a questionnaire is being developed and implemented that addresses the development of metacognition skills of the students as the semester progresses. Based on the current student performance data, there has been a marginal improvement in their scores. However, the more significant changes that has been observed is in the increased student engagement in lecture discussion and office hours. This is an indication that students are more involved in critical thinking which aids in their learning and less on outside help (such as solution manuals).

\section{Introduction}

Engineering is a profession where engineers must come up with creative ideas to solve a problem in hand. This in turn relies on an engineer's experience, a strong grounding on conceptual knowledge, and of course in skill sets.

A course in Dynamics is part of a series of courses in Engineering Mechanics, the others being Statics and Mechanics of Materials. In a Mechanical Engineering curriculum, it is an important pre-requisite for courses in Dynamical Systems, Fluid Dynamics, and Mechanisms and Machines. Therefore, a clear conceptual understanding of the basic principles of Dynamics is warranted, so that students can undertake critical thinking in future courses and in their professional career.

The principles of Dynamics, as part of a course in Engineering Mechanics, is better understood by intensive problem solving. Because of limited time in classroom lectures, problem solving in homework assignements is an integral part of the learning activities undertaken by the student. Unfortunately, in recent years, extensive use of solution manuals and replication of answers from the solution manual without any understanding has been a major hurdle in the learning process of 
the students. Blind faith in the solution manual rather their own abilities to solve problems negatively impacts a student's conceptual understanding of the principles of Dynamics and therefore impedes their critical thinking ability. This is a nationwide phenomenon [1], [2], [3] and some important reasons has been traced to - (a) students who are employed outside school find less time in their studies, (b) lack of mathematical and analytical skills discourages students from trying on their own, and (c) instant gratification of just getting the answer.

Taking a cue from educational psychology [4], an approach to circumvent the negative impact of solution manuals is by changing problem features (examples include the format of the problem statement, familiarity with the problem context, and whether the values provided are numeric or symbolic). Sweller and colleagues ([5],[6], and [7]) have shown that one effective way to accomplish this goal is to have students engage in open-ended problem solving rather than attempt to reach a particular goal (for example, "calculate the value of as many variables as you can " versus "what is the final velocity of the car?"). As noted in these studies, such a technique has had success in high school courses in geometry and trigonometry.

In the subsequent sections of this manuscript, we first describe the nature of the Dynamics course in our institution and provide two examples of open-ended homework problems. This is followed by a section that describes the steps taken to measure the efficacy of such an approach and a questionnaire developed to gauge the development of metacognition skills as the semester progresses. This study is a work in progress and therefore we describe the preliminary results from fall 2018.

\section{Nature of the Dynamics course and examples of open-ended homework problems}

The course in Dynamics is offered in spring and fall semesters. It is a three-credit course which meets for an hour, three times a week. The author of this manuscript has been an instructor for two sections of this course for the past nine years (or eighteen semesters). Each section has between 30-35 students. The pedagogical style has been the regular instructor delivered classroom lecture. The problems solved during the lecture are mostly well-defined closed problems but beginning in fall 2018 it has also included open-ended problems. The lecture problems are solved on an interactive basis (a hybrid Shanghai Math model) with the students. Such a style of lecture delivery relies heavily on student involvement and increases the student engagement. Every lecture has a homework assignment, and the nature of homework problems and its level of difficulty is similar to the problems solved in classroom lectures. The weekly quizzes (for fifteen minutes), the three midterm exams (for one hour), and the final exam (for two hours) are based on well defined, closed problems and not the open-ended problems.

In mechanics (where the physics of most of the problems is definitive), problems may have a unique solution. In accordance to literature in educational psychology ([4]-[7]), open-ended problems (with unique solutions) implies problems where multiple pathways to the solution exists with varying level of mathematical complexities. The task of the student is to think ahead before opting for a particular method of solution.

The analysis of the efficacies of open-ended problem in student learning in Dynamics is a work in progress. In fall 2018, a dozen of such problems was tested for the first time as homework 
assignments. Not all close ended textbook problems can be re-formulated as an open-ended problem. Some amount of research is required which includes the various approaches needed to solve the problem vis-à-vis the mathematical abilities of the students.

For brevity, two such problems are described, which are altered version of problems in [8]:

\section{$\underline{\text { sample open-ended problem } 1 \text { (from particle dynamics) }}$}

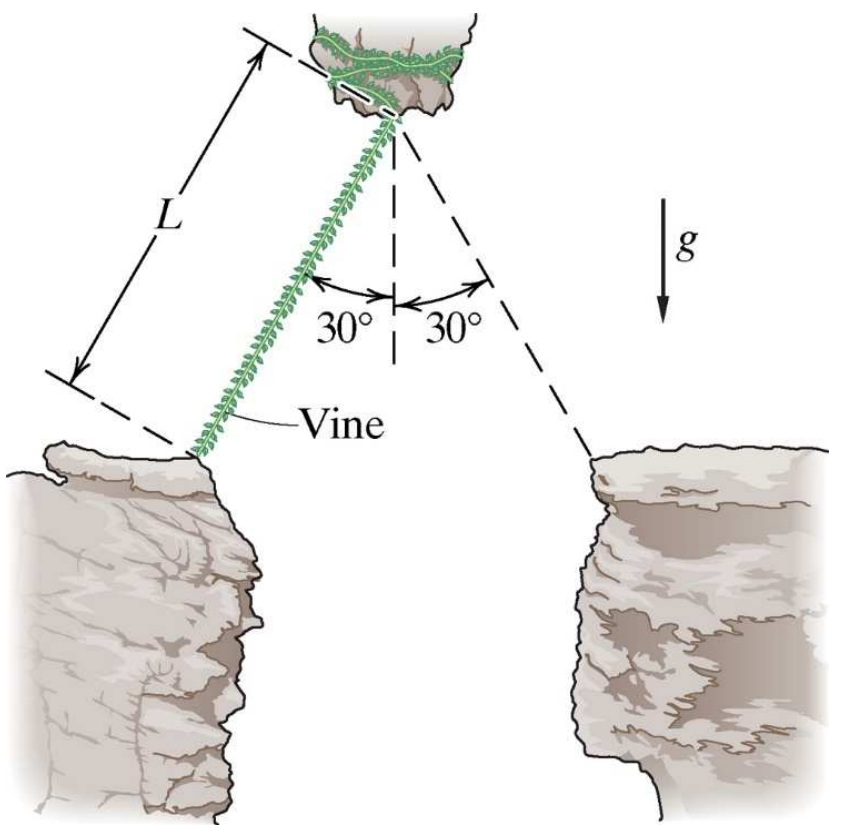

For a scene in a new movie, an actor has to grab a hanging vine and swing across a canyon. The tensile breaking strength (of the vine) is $T_{\max }$.

Assuming that the actor has a mass of $m$ and can be treated as a mass particle, determine the conditions under which the stunt can be completed successfully.

Assume that the actor begins the swing by stepping off the ledge with essentially zero velocity.

$\underline{\text { sample open-ended problem } 2 \text { (from rigid body dynamics) }}$

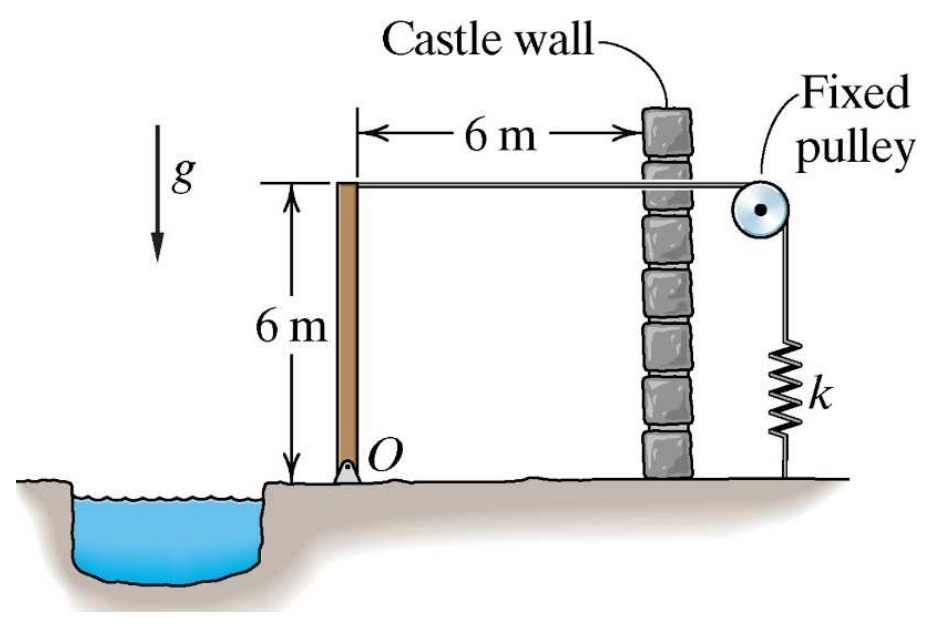

As your first job out of college, you have been assigned the task of helping design a drawbridge (see adjoining figure) for your eccentric employer. The drawbridge (you can approximate its geometry as a thin slender rod), freely hinged at the end $O$, has a length of $6 \mathrm{~m}$, a mass of $450 \mathrm{~kg}$. A mass-less rope is attached to the end of the drawbridge, passes through the castle wall, then passes over a mass-less pulley, and is attached to a spring (of spring constant $k$ ). In the up position of the bridge, the spring is un-extended. A colleague has already constructed most of it, and all you need to do is finish up the final details.

Determine whether, when built the drawbridge will "work"; that is, when nudged from the vertical, will it continue down rather than being pulled back up to the vertical position due to the action of 
the stretched spring? Show your work mathematically and assume the slender rod rotates about $O$ with a rotational speed of $0.5 \mathrm{rad} / \mathrm{s}$.

\section{Constructing an assessment rubric for student performances}

Based on Wood's problem-solving methodology ([2], [9]), data is collected from the student's responses to the open-ended homework problems on six of the seven steps - engage, define, explore, plan, implement, check, and reflect. Data on student engagement is collected from the response the students gave to a questionnaire. For brevity, the rubric for step 1 (student engagement) and step 4 (planning) is indicated in Table 1 and 2 in Appendix 1. The data was collected for each of the twelve open-ended homework questions and averaged at the end of the semester.

Besides, a second questionnaire is constructed for a qualitative metacognitive analysis when solving the open-ended homework questions. This was administered at the end of the semester. The questions included -

(a) What was the greatest challenge you faced in solving open-ended problems at the beginning of the semester? As the semester progressed, how did you overcome the challenge?

(b) What did you think about the concept of solving open-ended problems in the beginning of the semester? What do you think now at the end of the semester?

(c) What general skills did you learn (applicable to other classes/situations) from solving open-ended problems in this class?

(d) Do you have any specific suggestions for the instructor on how he can help students improve their problem-solving skills?

(e) Do you have any specific suggestions for students who try to solve open-ended problems?

\section{Results}

This study which is a work in progress was initiated for the first time in fall 2018 . We discuss the results based on student engagement and the grades earned in the course in dynamics.

Student engagement: Prior to implementing open-ended problems in this course, problems solved in class lectures and assigned in homework where all from textbook and close-ended. Student engagement were mainly confined to classroom lectures with minimal attendance in office hours because of readily available solution manuals.

Therefore, when viewed from the point of view of increased student engagement (and therefore weaning them away from solution manuals), the exercise has been a success. This can be viewed from the data in Table 1 (step 1 in student engagement) in Appendix 1.

Table 2 (step 4 on plan to solve a problem) in Appendix 1 indicates majority of the students could work on a model and be able to break down the problem and list the variables that needs to be found. This is an improvement because when replicating answers from a solution manual, steps to solve problems are not clearly delineated. 
As far as improved understanding and learning is concerned, the questionnaire for metacognitive analysis elicited responses such as "time spent on homework increases, but with help from fellow students and instructors, it is manageable", "I find them more meaningful than regular homework problem", and "Think about the problem holistically, sketch and research before attempting any calculations".

Assessment in terms of grades earned: The open-ended problems were solved in classroom lecture and as part of homework assignments. The ten weekly quizzes (for fifteen minutes), the three midterm exams (for duration of an hour), and the final exam (for two hours) were based on well-defined closed problems, and not open-ended problems.

We consider the grade point average earned by a student in a course dynamics. The grades awarded are A (4 points), A- (3.7 points), B+ (3.3 points), B (3 points), B- (2.7 points), C+ (2.3 points), $\mathrm{C}$ ( 2 points), $\mathrm{C}-$ (1.7 points), $\mathrm{D}+$ (1.3 points), $\mathrm{D}$ (1 point), and $\mathrm{F}$ (0 point). Grades $\mathrm{A}$ to $\mathrm{B}$ are strictly competitive, grades B- to C- are awarded based on the progress made and effort put in by the students during the entire semester, and grades $\mathrm{D}+$ to $\mathrm{F}$ are awarded if no progress is observed during the entire semester. The grade point average earned in the course in fall 2018 will be the experimental group (F18 with $n=63$ ) while the grades earned in fall 2017 will be the control group (F17 with $n=59$ ). The grades from the course in spring 2018 is not considered because there was a change in instructor in April 2018, when the author had to tend to some unexpected family exigencies. The final exam in fall 2017 and fall 2018 was essentially identical (students do not get back the solutions of the final exam).

To investigate the effect of the open-ended problems on student learning a standard significance testing is used. The null hypothesis $\left(H_{0}\right)$ and the alternative hypothesis $\left(H_{1}\right)$ is articulated as $H_{0}$ : There is no difference in relative learning between F18 and F17.

$H_{1}$ : There is demonstrable difference in relative learning between F18 and F17.

Following Pfahl et. al. ([10]), the hypothesis is tested by applying a one-way paired t-test which requires the scores follow a normal distribution. Although no normal distribution of the scores could be assumed a priori, most scores were distributed within the range of \pm 1 standard deviation around the sample means. No outliers were detected. The significance level $\alpha$ was set at 0.05 .

Table 3 summarizes the descriptive statistics of the two groups. The first 3 rows indicate the mean, median, and the standard deviation of the two groups. The last three rows indicate the testing of the hypothesis. With a p-value of 0.0413 , the data indicates that the null hypothesis can be rejected. Therefore, if viewed from the point-of-view of overall grade in the course, then inclusion of open-ended problems had marginal improvement.

\section{Discussion and Future Directions}

Initial results collected from student responses and grade point average of their scores in a course in dynamics indicate the plausible positive role open-ended problems might play in improved student learning. Over the next three years, more open-ended problems will be formulated, and more data will be collected from the course in dynamics and subsequent courses that the students 
will enroll. Analysis of such data will give a more definite answer on the role open-ended problems play in improved student learning and therefore minimizes the effects of readymade solution manuals.

\section{Bibliography}

1. D. Belkin, "Exclusive Test Data: Many Colleges Fail to Improve Critical-Thinking Skills," The Wall Street Journal, June 5, 2017.

2. N.J. Mourtos, "Challenges Students Face in Solving Open-Ended Problems," International Journal of Engineering Education, Vol. 26, No. 4, pp. 846-859, 2010.

3. D. Adair and M. Jaeger, "Incorporating Critical Thinking into an Engineering Undergraduate Learning Environment," International Journal of Higher Education, Vol. 5, No. 2, pp. 23-39, 2016.

4. S.R. Singer, N.R. Nielsen, and H.A. Schweingruber, "Discipline-Based Education Research: Understanding and Improving Learning in Undergraduate Science and Engineering," The National Academy Press, 2012.

5. J.Sweller and M.Levine, "Effects of goal specificity on means-ends analysis and learning," Journal of Experimental Psychology: Learning, Memory, and Cognition, Vol. 8, pp. 463-474, 1982.

6. J.Sweller, R. Mawer, and M. Ward, "Development of expertise in mathematical problem solving," Journal of Experimental Psychology: General, Vol. 112, pp. 634-656, 1983.

7. E. Owen, J. Sweller, "What do students learn while solving mathematical problems?" Journal of Educational Psychology, Vol. 77, pp. 272-284, 1985.

8. B.H. Tongue, Dynamics: Analysis and Design of Systems in Motion, Wiley, 2010.

9. D.R. Woods, Problem-based learning: How to gain the most from PBL, Watertown, ON, 1994.

10. D. Pfahl, O. Laitenberger, G. Ruhe, J. Dorsch, and T. Krivobokova, "Evaluating the learning effectiveness of using simulations in software project management education: results from a twice replicated experiment.", Information and Software Technology, Vol 46, pp. 127-147, 2004.

11. M.M.Waldrop, "The Science of Teaching Science", Nature, Vol. 523, pp 272-274, 2015.

\section{Appendix 1}

Table 1: Rubric to measure student engagement (Total number of students two sections combined $=63$. OEP stands for open-ended problems)

\begin{tabular}{|l|l|l|l|l|}
\hline $\begin{array}{l}\text { How often have you done each of the following in } \\
\text { connection with one of the OEPs? }\end{array}$ & Never & $\begin{array}{l}1 \text { to 2 } \\
\text { times }\end{array}$ & $\begin{array}{l}3 \text { to 5 } \\
\text { times }\end{array}$ & $\begin{array}{l}\text { More than } \\
5 \text { times }\end{array}$ \\
\hline Asked questions related to an OEP during class & $28 \%$ & $56 \%$ & $11 \%$ & $5 \%$ \\
\hline Contributed to a class discussion related to an OEP & $30 \%$ & $54 \%$ & $13 \%$ & $3 \%$ \\
\hline $\begin{array}{l}\text { Prepared two or more drafts of the solution of these } \\
\text { problems before turning them in }\end{array}$ & $7 \%$ & $78 \%$ & $11 \%$ & $4 \%$ \\
\hline $\begin{array}{l}\text { Worked with classmates outside of class to prepare } \\
\text { OEPs solutions }\end{array}$ & $2 \%$ & $37 \%$ & $37 \%$ & $24 \%$ \\
\hline Helped other students with the solution of OEP & $28 \%$ & $41 \%$ & $20 \%$ & $11 \%$ \\
\hline $\begin{array}{l}\text { Used email to communicate with the course instructor } \\
\text { regarding OEPs }\end{array}$ & $77 \%$ & $15 \%$ & $4 \%$ & $4 \%$ \\
\hline $\begin{array}{l}\text { Visited the course instructor in his office to discuss } \\
\text { OEPs }\end{array}$ & $35 \%$ & $39 \%$ & $19 \%$ & $7 \%$ \\
\hline $\begin{array}{l}\text { Discussed ideas related to OEPs with others outside } \\
\text { of class (students, family members, coworkers, etc.) }\end{array}$ & $14 \%$ & $54 \%$ & $17 \%$ & $15 \%$ \\
\hline
\end{tabular}


Table 2: Rubric to measure the planning by students in solving an OEP

\begin{tabular}{|l|l|}
\hline $\begin{array}{l}\text { Select an appropriate model for developing a solution, break down the } \\
\text { problem into sub-problems, and determine what needs to be found in each } \\
\text { sub-problem }\end{array}$ & $\%$ of students \\
\hline $\begin{array}{l}\text { Selects the most appropriate model for developing a solution, break down } \\
\text { the problem into sub-problems, and provides complete list of what needs to } \\
\text { be found in each sub-problem }\end{array}$ & $7 \%$ \\
\hline $\begin{array}{l}\text { Select the most appropriate model for developing a solution, break down the } \\
\text { problem into sub-problems, and provides incomplete list of what needs to be } \\
\text { found in each sub-problem }\end{array}$ & $33 \%$ \\
\hline $\begin{array}{l}\text { Selected model for developing a solution is not described adequately; } \\
\text { breakdown of problem into sub-problems is not appropriate or helpful; list of } \\
\text { what needs to be done is incomplete }\end{array}$ & $35 \%$ \\
\hline $\begin{array}{l}\text { Does not identify a model for developing a solution or does not break down } \\
\text { the problem into sub-problems and / or does not list what needs to be done }\end{array}$ & $22 \%$ \\
\hline Does not attempt & $3 \%$ \\
\hline
\end{tabular}

Table 3: Testing of hypothesis in terms of performance grade point average earned in the course

\begin{tabular}{|l|l|l|l|l|}
\hline Semester & mean & median & Standard Deviation \\
\hline $\begin{array}{l}\text { Fall 2018 } \\
\text { (experimental group) }\end{array}$ & 2.07 & 2.3 & 1.04 & \\
\hline $\begin{array}{l}\text { Fall 2017 (control } \\
\text { group) }\end{array}$ & 1.91 & 2.15 & 0.94 & p-value \\
\hline \multicolumn{5}{|c|}{ Testing of Hypothesis } \\
\hline $\begin{array}{c}\text { Cohen's } d \text { effect } \\
\text { size }\end{array}$ & $\begin{array}{c}\text { degrees of } \\
\text { freedom }\end{array}$ & t-value & Crit.to.90 & 0.0413 \\
\hline 0.558 & 111 & 1.953 & 1.299 & \\
\hline
\end{tabular}

